ORIGINAL ARTICLE

\title{
Onset of breast and pubic hair development in 1231 preadolescent Lithuanian schoolgirls
}

\author{
S Žukauskaitè, D Lašienè, L Lašas, B Urbonaitè, P Hindmarsh
}

Arch Dis Child 2005;90:932-936. doi: 10.1136/adc.2004.057612

See end of article for authors' affiliations .....................

Correspondence to: Dr S Zukauskaite, Institute of Endocrinology, Kaunas University of Medicine, Eiveniu 2, 50010 Kaunas, Lithuania; s.zukauskaite@ centras. It

Accepted 29 March 2005 Published Online First 26 April 2005

Background: Correct staging of puberty is essential in order to differentiate different pathologies, as various components of the endocrine system influence breast, pubic, and axillary hair development.

Aims: To determine the current timing of adrenarche and breast development in Lithuanian preadolescent schoolgirls.

Methods: Cross-sectional study of 1231 schoolgirls aged 7.0-11.6 years. Puberty was staged according to the method of Tanner. Mean age at entry into each pubertal stage was calculated by probit analysis. Results: Of the 255 girls aged 7 years, two had premature adrenarche $(0.8 \%)$ and one premature thelarche (0.4\%). Mean age of onset of pubic/axillary hair development was 11.0 years, and for breast development (Stage 2) 10.2 years. Breast Stage 3 development was attained at 11.3 years and Stage 4 at 13.9 years. Mean BMI, height, weight, and systolic blood pressure SD scores were higher in pubertal than in prepubertal girls. Skinfold thickness was also significantly higher in girls with isolated adrenarche than in prepubertal girls. The increase in BMI and weight resulted from an increase in body fat as evidenced by measures of subscapular and triceps skinfold thickness. Girls with only signs of adrenarche or thelarche did not differ from each other from the anthropometric standpoint.

Conclusions: Premature thelarche and premature adrenarche were relatively uncommon in this population. Pubertal onset was slightly earlier than the UK Tanner standards and tended to occur in girls with a higher BMI.

$F$ ollowing a period of relative quiescence during childhood the onset of puberty is heralded by an increase in the nocturnal secretion of gonadotropin releasing hormone (GnRH) towards the end of the first decade of life. ${ }^{1}$ In girls, the increase in oestradiol secretion results in breast development, which is present in about $3 \%$ of girls by their ninth birthday. ${ }^{2}$ In contrast, adrenarche and the resulting pubic and axillary hair development results from an increase in adrenal androgen secretion at about 6-8 years of age and is not associated with an increase in sensitivity of gonadotropins to GnRH or with sleep associated LH secretion characteristic of puberty. Adrenarche and gonadarche are two separate maturational events. ${ }^{34}$

A number of reports have suggested that there is still an ongoing trend towards earlier pubertal development in Western countries ${ }^{56}$ but that the timing of menarche has changed little. Rating of pubertal stage can be difficult particularly if self-reporting schemes are used. ${ }^{78}$ Separating the physical components of puberty is essential to provide robust epidemiological data, aid clinical diagnosis as different endocrine systems influence breast or pubic and axillary hair development, and aid prognosis-for example, exaggerated and/or premature adrenarche in childhood may have consequences in later life such as ovarian hyperandrogenism, polycystic ovary syndrome, and insulin resistance. ${ }^{9-11}$ In small or chronically ill children adrenarche is typically delayed, while in obese or large children it is early and often exaggerated. ${ }^{12}{ }^{13}$ Girls who mature early are shorter in adulthood, despite having greater peak height velocity and post-menarcheal increment in height. ${ }^{14}$ More advanced pubertal development is associated with an increased level of eating disturbance. ${ }^{15}$

The first decade of Lithuanian independence, since 1990, was marked by rapid political and economic changes. Transition into market economics, the appearance and intensive advertising of new products, and the incorporation of Western lifestyle made an impact on the health behaviour of the population. Positive trends in the nutritional habits of Lithuanians were observed (for example, the consumption of vegetable oil for cooking, and increased consumption of fresh fruits and vegetables). ${ }^{16}$ However, some studies showed negative trends in health behaviour in certain groups of the population; for instance, smoking substantially increased among teenagers and adult women, and increased alcohol consumption was recorded among schoolchildren. ${ }^{17}$ These phenomena could indicate that pubertal timing in children might also have been altered during the last 15 years. To determine the current prevalence of clinical signs of adrenarche and breast development in Lithuanian preadolescent schoolgirls, a pilot cross-sectional community based study was undertaken over the period 1999 to 2000.

\section{METHODS}

\section{Subjects}

A total of 1231 schoolgirls, from a variety of social backgrounds, aged 7.0-11.6 years in the first four grades of Lithuanian primary or secondary schools of Vilnius city $(\mathrm{n}=845)$ and Kaunas region $(\mathrm{n}=386)$ were studied. Pubertal staging was recorded as part of the routine paediatric assessment conducted in the schools. A total of 443 girls from four schools were unselected-that is, all girls attending the school participated, whereas in the five remaining schools participation varied from 55\% in one school $(\mathrm{n}=81)$ to $80-85 \%$ in the others (numbers of participants: $149 ; 166 ; 142 ; 250)$. About $3 \%$ of the participants had chronic diseases such as asthma, epilepsy, congenital heart disease, and chronic pyelonephritis. There was no difference in age, body mass index, or prevalence of chronic diseases between those that participated and those

Abbreviations: $\mathrm{BP}$, blood pressure; $\mathrm{BMl}$, body mass index; $\mathrm{GnRH}$, gonadotropin releasing hormone; $\mathrm{LH}$, luteinising hormone 


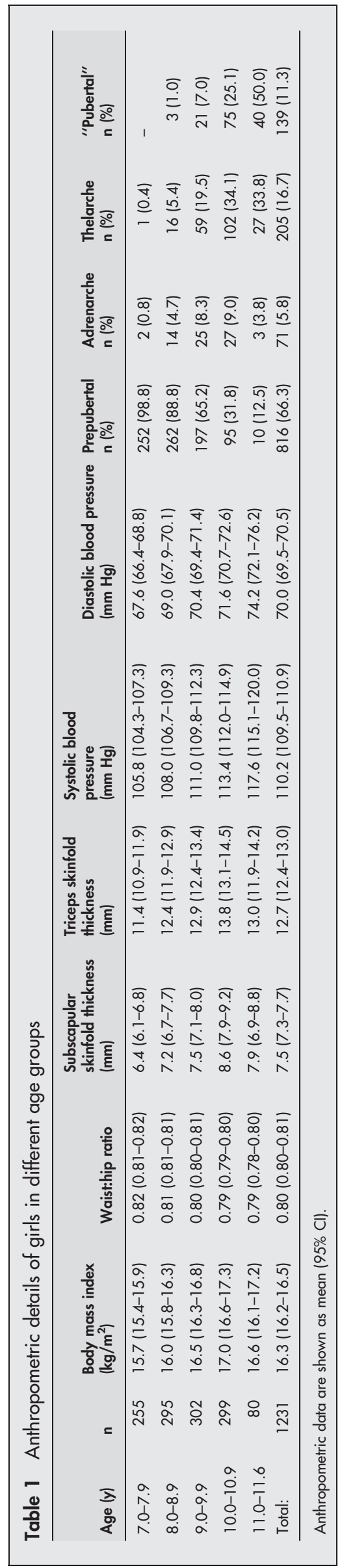

that did not. Informed consent to participate was obtained from the parents and assent from the children where appropriate. The study was approved by the Ethics Committee for Biomedical Research of Kaunas region.

Pubertal development was staged by the same paediatric endocrinologist (SZ) using the method of Tanner. ${ }^{18}$ Mean age of onset of adrenarche and thelarche were compared with previous Lithuanian data, collected between 1984 and $1985 .{ }^{19}$ Premature adrenarche and premature thelarche were considered when there were signs of pubic/axillary hair development and breast development respectively present before the age of 8 years. All girls were checked for presence of hirsutism by inspection. Height $(\mathrm{cm})$ and weight $(\mathrm{kg})$ were recorded at examination and body mass index $\left(\mathrm{kg} / \mathrm{m}^{2}\right)$ derived. Skinfold thickness $(\mathrm{mm})$ was measured at subscapular and triceps sites using Holtain calliper (LTD, Crymych, UK). Hip and waist circumferences $(\mathrm{cm})$ were recorded and the waist-to-hip ratio calculated. Daytime blood pressure (BP) was measured using aneroid sphygmomanometer with appropriate cuff sizes. For some analyses participants were grouped by one year age intervals.

\section{Statistical analysis}

Estimates for mean age at entry into a pubertal stage were calculated by probit analysis from the proportions of girls with the characteristic at different ages. Probit analysis is the procedure that measures the relation between the strength of a stimulus and the proportion of cases exhibiting a certain response to the stimulus. It is useful for situations where there is a dichotomous output that is thought to be influenced or caused by levels of some independent variable(s). Probit regression is an alternative log-linear approach to handling categorical dependent variables.

Anthropometric data were expressed as means with 95\% CI. BMI, height, weight, and skinfold thickness at triceps and subscapular sites were expressed as standard deviation scores (SDS) using 1996 Growth Reference Data of Dutch children ${ }^{20}$ to allow comparisons at different ages. Blood pressure was also expressed as an SDS using data from the Second Task Force on Blood Pressure Control in Children. ${ }^{21}$ Cross-sectional associations between age and different anthropometric characteristics, and their SDS, as well as between waist-tohip ratio and other variables, were assessed by Pearson's correlation coefficient. Mean BMI SDS, skinfold thickness SDS, and waist-to-hip ratio between independent groups of different pubertal status were compared by multivariate analysis of variance (ANOVA), corrected by Scheffé's test for multiple comparisons. Statistical significance was considered when $\mathrm{p}<0.05$.

\section{RESULTS}

General

Anthropometric and pubertal staging data are shown in table 1. Girls with pubic (Stages P2-P4) and/or axillary hair alone were denoted as "adrenarche", signs of breast development (Stages B2-B4) alone as "thelarche", and those with a combination of the two characteristics "pubertal". As expected, mean age differed between each of the group's puberty $(p<0.005)$. Anthropometric data according to pubertal status are shown in table 2 .

\section{Timing of secondary sexual characteristics}

Figure 1 shows the proportion of girls with different pubertal status presented in yearly increments of age. Mean age for onset of breast development was 10.2 (95\% CI 10.1 to 10.3 ) years, attainment of Breast Stage 3 was at 11.3 (95\% CI 11.1 to 11.6) years, and Breast Stage 4 was estimated to begin at 13.9 (95\% CI 12.6 to 18.5$)$ years. 


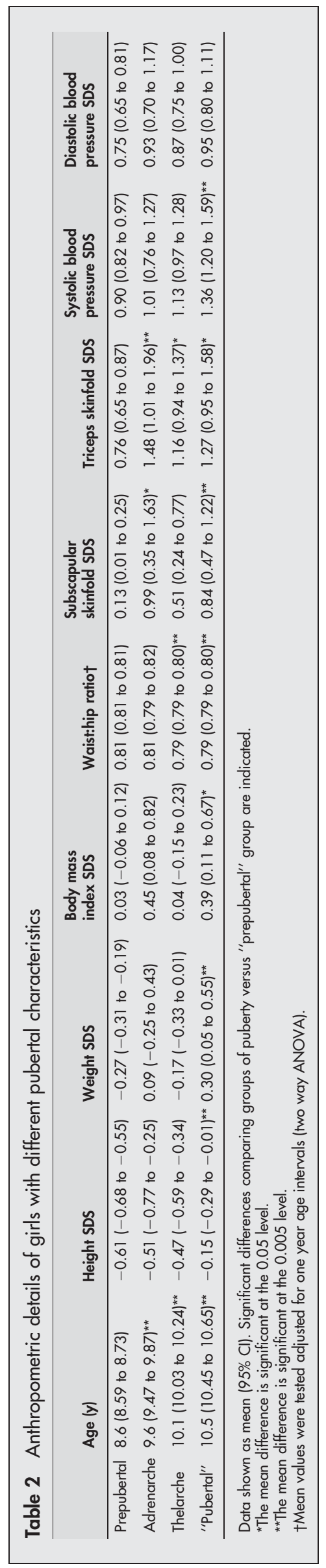

Pubic hair development was observed at an average age of 11.2 (95\% CI 10.9 to 11.5$)$ years. As appearance of axillary hair was the only sign of adrenarche in some cases $(9.5 \%)$, an "overall adrenarche" (presence of pubic and/or axillary hair) was estimated at 11.0 (95\% CI 10.8 to 11.3 ) years. Mean age for the onset of axillary hair was 12.7 (95\% CI 12.1 to 13.7 ) years. Of the 415 girls who showed signs of pubertal maturation, $17 \%$ had signs of adrenarche without signs of breast development. Twenty two girls had some symptoms of hypertrichosis but none showed evidence of true hirsutism.

Age at onset of Breast Stage 2 was younger than Lithuanian Standard ${ }^{19}$ developed 15 years ago (11.5 years, range 9-16; $p<0.01$ ). However the onset of clinical signs of adrenarche remains about the same-the onset of pubic hair development between 1984 and 1985 was 11.1 (range 10-15) years $(\mathrm{p}>0.05)$.

\section{Anthropometric measures}

There was a weak trend to a decrease in height SDS $(\mathrm{r}=-0.13)$ and weight SDS $(\mathrm{r}=-0.11)$, but no trends of skinfold thickness SDS with age in the whole group. Waistto-hip ratio correlated negatively with age $(r=-0.26)$.

Mean BMI, height, and weight SDS were higher in girls in puberty than those who were prepubertal (table 2). Mean BMI SDS was also higher in girls with isolated adrenarche than in prepubertal group; however the difference was not statistically significant $(p=0.11)$. The increase in BMI was reflected in measures of subscapular and triceps skinfold thickness. Girls with thelarche only had significantly lower height $(\mathrm{p}<0.05)$, weight $(\mathrm{p}<0.01)$, and skinfold thickness at triceps site SDS $(p<0.05)$ than the "pubertal" group. No significant differences in height, weight, BMI, skinfold thickness, and blood pressure SDS were detected between girls with signs of breast development and girls with pubic/ axillary development.

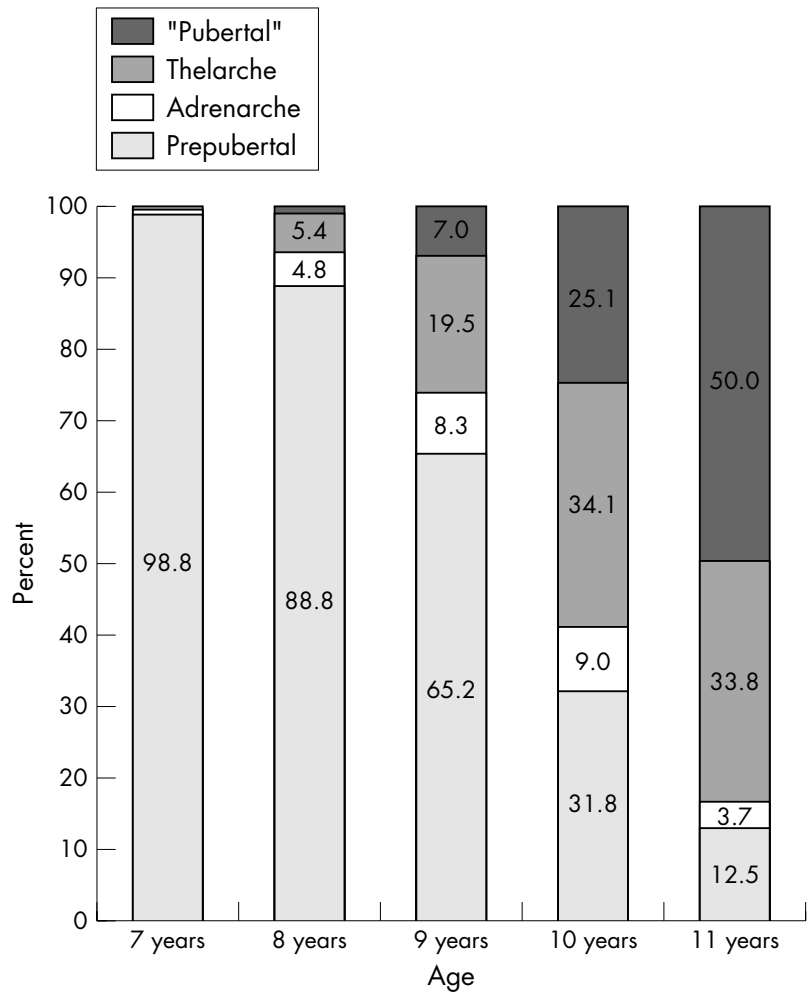

Figure 1 Proportions of the preadolescent girls with different pubertal status according to age. 


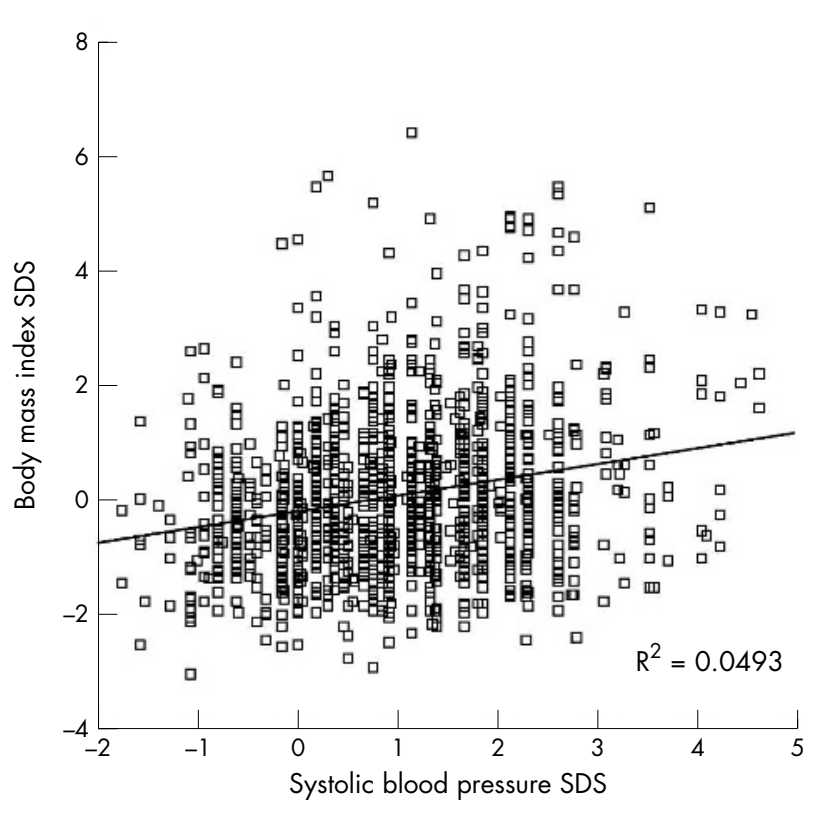

Figure 2 Scatterplot of body mass index SDS versus systolic blood pressure SDS with regression line in all girls.

Waist-hip ratio was related with subscapular skinfold thickness SDS $(r=0.20$ analysing all girls, $r=0.46$ in the "adrenarche" group, p $<0.01$ ). There was no significant correlation of waist-hip ratio with triceps skinfold thickness SDS, except when the "adrenarche" and "pubertal" groups were considered separately $(\mathrm{r}=0.34, \mathrm{r}=0.23$ respectively).

By multivariate two way ANOVA, within the same age groups, girls with thelarche only and girls with signs of thelarche and pubarche ("pubertal") had lower mean values of waist-hip ratio than prepubertal girls ( $p<0.001$, Table 2 ). This ratio was not significantly different between the "adrenarche" group and other girls in the same age groups.

\section{Blood pressure}

Day time systolic and diastolic blood pressure SDS were weakly related to skinfold thickness SDS and BMI SDS ( subscapular skinfold thickness $r=0.19$, and $r=0.17$ respectively; triceps skinfold thickness $\mathrm{r}=0.19$, and $\mathrm{r}=0.18$ respectively, BMI SDS $\mathrm{r}=0.22, \quad \mathrm{r}=0.19$ respectively). Relation between body mass index SDS and systolic blood pressure SDS in all girls is shown in fig 2. Waist-hip ratio was only related to daytime blood pressure SDS in girls aged 11 years and above $(r=0.25)$. No differences in diastolic BP SDS between different groups of puberty were found.

\section{DISCUSSION}

In this community based study we documented a slightly earlier onset of Breast Stage 2 development at 10.2 years compared to the UK Standard ( 11.2 years, $\mathrm{p}<0.01)^{18}$ and to the Lithuanian Standard. Despite onset of breast development occurring slightly earlier, the onset of clinical signs of adrenarche remains the same. Our observations are consistent with a 1985 study of Lithuanian children, which documented a mean age of menarche of 13.4 (SD 1.1) years, ${ }^{19}$ and a more recent report (1996-2000) that the mean age of menarche of Lithuanian girls was 13-13.5 years in cities and 13.5-14 years in rural areas..$^{22}$ To ascertain whether earlier onset of Breast Stage 2 in our girls could be attributed to a slower tempo of pubertal process, longitudinal observations would be needed.

With respect to the other signs of secondary sexual development, about $5 \%$ of girls aged 8 years had pubic/ axillary hair without breast development-that is, maturing through adrenarche pathway, as did $8 \%$ of girls aged 9 years, $9 \%$ of girls aged 10 years, and $4 \%$ aged 11 years. Premature and early adrenarche, as well as premature thelarche was a relatively uncommon finding in this population, and certainly not at the level that has been suggested in other studies. $^{510}$ This probably reflects the fact that this is a population based study which gives a better estimate of prevalence than clinic based practice. Other clinical symptoms of hyperandrogenism, such as hirsutism, were not found in this population. It is possible that we have underestimated the prevalence as we did not evaluate such symptoms as accelerated growth and adult type perspiration (possible signs of endogenous androgens), ${ }^{23}$ although it is unlikely that they would alone have contributed to the discrepancy between our rate and that from the USA of $6.7 \% .^{5}$ The pattern of hyperandrogenism in premature and exaggerated adrenarche resembles the overproduction of adrenal androgens seen in polycystic ovary syndrome. ${ }^{24}$ Whether these groups of girls have an increased risk for hyperinsulinism and hyperandrogenism in future, needs further evaluation.

A relatively early menarche in girls seems to be associated with a trunk oriented fat distribution pattern from adolescence into adulthood. ${ }^{25}$ Girls with true puberty had significantly higher mean BMI, height, weight, skinfold thickness, and systolic BP SDS than prepubertal girls. Girls with isolated adrenarche also showed higher (however, not significantly) BMI SDS and significantly higher skinfold thickness than the prepubertal group. Girls with isolated adrenarche or thelarche did not differ significantly in their BMI, height, weight, and skinfold thickness SDS from each other. These results differ slightly from the study of Biro and colleagues, ${ }^{26}$ where females who enter puberty through the thelarche pathway, compared with the adrenarche pathway, had greater sum of skinfold thicknesses, BMI, and percent body fat one year before the onset of, as well as throughout puberty.

Multivariate analysis in this cross-sectional study showed that a higher BMI, as well as higher skinfold thickness were associated with early puberty. This is consistent with the hypothesis that fat mass is a facilitatory factor for the timing of puberty in girls. ${ }^{27}$ In particular, rapid growth in height and weight in the first year of life leads to an increase in size compared to national standards, but the increase is less than the overall secular trend in height. This would imply that mechanisms must operate to narrow the gap between this induced growth and genetic potential, and altering the timing of puberty may be one such mechanism..$^{28}$ This might also explain the slight negative trend of height SDS with age in this population, with the earlier onset of puberty returning the height trajectory back towards the genetically determined stature.

Truncal fat deposits were positively related to waist-hip ratio in this study, confirming that they are good field indicators of intra-abdominal fat deposition..$^{29}$ Increased BMI, truncal fat distribution, and increased blood pressure are all independent risk factors for cardiovascular disease. ${ }^{30}$ In this study within the same age group, prepubertal girls had significantly lower systolic BP SDS than "pubertal" girls, but no differences in blood pressure between girls developing through adrenarche and thelarche pathway were found. The relation between truncal obesity and blood pressure was only evident in girls aged 11 years. This probably reflects the amplification effect of blood pressure differences with age ${ }^{31}$ along with the need in younger age groups for larger sample sizes to detect differences in blood pressure. For example, a sample size of 400 children at age 5 years is required to detect a $5 \mathrm{~mm} \mathrm{Hg}$ difference in systolic blood pressure. ${ }^{32}$ 


\section{What is already known on this topic}

- A number of reports have suggested that there is still an ongoing trend towards earlier pubertal development in Western countries but that the timing of menarche has changed little

- Exaggerated and/or premature adrenarche in childhood may have consequences in later life such as ovarian hyperandrogenism, polycystic ovary syndrome, and insulin resistance

Major changes have taken place in the Baltic States in the last 15 years. Despite these events there is little to suggest a change in the timing of pubic hair development and menarche. The data do suggest a slightly earlier timing of the onset of puberty (Breast Stage 2) in this population compared to the UK standard. Isolated thelarche and adrenarche appear to be uncommon in this population compared to other countries, ${ }^{45}$ reflecting in part the community based component of this study. An earlier onset of pubertal development appeared to be associated with an increase in body mass index, truncal fat, and higher blood pressure. Girls who start the pubertal development via thelarche pathway or adrenarche pathway did not differ from each other from the anthropometric standpoint.

\section{Authors' affiliations}

S Žukauskaitè, D Lašienè, L Lašas, B Urbonaitè, Institute of Endocrinology, Kaunas University of Medicine, Kaunas, Lithuania P Hindmarsh, Centre for Human Growth and Maturation, Cobbold Laboratories, Middlesex Hospital, University College London, London, UK

Competing interests: none declared

\section{REFERENCES}

1 Lee PA. Disorders of puberty. In: Lifshitz F, ed. Paediatric endocrinology, 3rd edn. New York: Marcel Dekker, 1996:175.

2 Brook CGD. Precocious puberty. Clin Endocrinol 1995;42:647-50.

3 Parker LN. Central control of adrenarche. In: Savage MO, Bourguinon JP, Grossman $A B$, eds. Frontiers in pediatric neuroendocrinology. Cambridge: Blackwell Scientific Publications, 1994:46.

4 Ibanez L, Dimartino-Nardi J, Potau N, et al. Premature adrenarche-normal variant or forerunner of adult disease? Endocr Rev 2000;21:671-96.

5 Herman-Giddens ME, Slora EJ, Wasserman RC, et al. Secondary sexual characteristics and menses in young girls seen in office practice: a study from the Pediatric Research in Office Settings network. Pediatrics 1997:99:505-12.

6 Bona G, Castellino N, Petri A. Secular trend of puberty. Minerva Pediatr 2002; 54:553-7

7 Taylor SJC, Whincup PH, Hindmarsh PC, et al. Performance of a new pubertal self-assessment questionnaire: a preliminary study. Paediatr Perinatal Epidemiol 2001;15:88-94.

8 Bonat S, Pathomvanich A, Keil MF, et al. Self-assessment of pubertal stage in overweight children. Pediatrics 2002;110:743-7.

9 Yen SCC. The polycystic ovary syndrome. Clin Endocrinol 1980;12:177-207.

10 Ibanez L, Potau N, Virdis R, et al. Postpubertal outcome in girls diagnosed of premature pubarche during childhood: increased frequency of functional ovarian hyperandrogenism. J Clin Endocrinol Metab 1993;76:1599-603.

11 Oppenheimer E, Linder B, DiMartino-Nardi J. Decreased insulin sensitivity in prepubertal girls with premature adrenarche and acanthosis nigricans. J Clin Endocrinol Metab 1995:80:614-18.

12 Kaplowitz PB, Slora EJ, Wasserman RC, et al. Earlier onset of puberty in girls: relation to increased body mass index and race. Pediatrics $2001 ; 108: 347-53$.

\section{What this study adds}

- This population based study suggests that premature thelarche and premature adrenarche are relatively uncommon in girls of Eastern European origin

- Onset of thelarche was slightly earlier than the UK Tanner standards, but there was no obvious difference in the onset of pubic hair appearance and in the projected onset of menarche

- Girls who start the pubertal development via thelarche pathway or adrenarche pathway did not differ from each other from the anthropometric standpoint

13 Winter JSD. Development of the pituitary-adrenal axis in childhood and adolescence. In: Savage MO, Bourguinon JP, Grossman AB, eds. Frontiers in pediatric neuroendocrinology. Cambridge: Blackwell Scientific Publications, 1994:57.

14 Biro FM, McMahon RP, Striegel-Moore R, et al. Impact of timing of pubertal maturation on growth in black and white female adolescents: The National Heart, Lung, and Blood Institute Growth and Health Study. J Pediatr $2001 ; 138: 636-43$

15 Koff E, Rierdan J. Advanced pubertal development and eating disturbance in early adolescent girls. J Adolesc Health 1993;14:433-9.

16 Grabauskas V, Petkeviciene J, Kriaucioniene V, et al. Health inequalities in Lithuania: education and nutrition habits. Medicina (Kaunas) 2004;40:875-83

17 Grabauskas V, Zaborskis A, Klumbiene J, et al. Changes in health behavior of Lithuanian adolescents and adults over 1994-2002. Medicina (Kaunas) 2004; 40:884-90.

18 Tanner JM. Growth at adolescence, 2nd edn. Oxford: Blackwell Scientific Publications, 1962.

19 Tutkuviene J. Lietuviu moteru vaisingasis periodas. (Fertile period of Lithuanian women). In: Balciuniene I, Nainys JV, Pavilonis S, Tutkuviene J, eds. Lietuviu antropologijos metmenys (Outlines of Lithuanian anthropology). Vilnius: Mokslas, 1991:39-60.

20 Gerver WJM, Bruin R. Paediatric morphometrics, a reference manual, 2nd edn. Utrecht: Bunge 1996. In: Growth Analyzer, CD. Version 1.0, Pijlhove, 2001.

21 Anon. Report of the Second Task Force on Blood Pressure Control in Children1987. Pediatrics 1987:79:1-25.

22 Tutkuviene J. Lietuviu vaiku epochiniai fizinès bukles kitimai (Secular trends of physical condition of Lithuanian children). In: Raugale A, ed. Vaiku ligos, Vol 1. (Children's diseases). Vilnius: Gamta, 2000:47.

23 Voutilainen R, Perheentupa J, Apter D. Benign premature adrenarche: clinical features and serum steroid levels. Acta Paediatr Scand 1983;72:7-711.

24 Auchus RJ, Geller DH, Lee TC, et al. The regulation of human P450c17 activity: relationship to premature adrenarche, insulin resistance and the polycystic ovary syndrome. TEM 1998:9:47-50.

25 van Lenthe FJ, Kemper HC, van Mechelen W, et al. Biological maturation and the distribution of subcutaneous fat from adolescence into adulthood: the Amsterdam Growth and Health Study. Int J Obes Relat Metab Disord 1996;20:121-9.

26 Biro FM, Lucky AW, Simbartl LA, et al. Pubertal maturation in girls and the relationship to anthropometric changes: pathways through puberty. J Pediatr 2003;142:643-6.

27 Garcia-Mayor RV, Andrade MA, Rios M, et al. Serum leptin levels in normal children: relationship to age, gender, body mass index, pituitary-gonadal hormones, and pubertal stage. J Clin Endocrinol Metab 1997;82:2849-55.

28 Cole TJ. Secular trends in growth. Proc Nutr Soc 2000;59:317-24.

29 Fox KR, Peters DM, Sharpe P, et al. Assessment of abdominal fat development in young adolescents using magnetic resonance imaging. Int J Obes Relat Metab Disord 2000;24:1653-9.

30 Hubert HB, Feinleib $M$, McNamara PM, et al. Obesity is an independent risk factor for cardiovascular disease: a 26 -year follow-up of participants in the Framingham Heart Study. Circulation 1983;67:968-77.

31 Law CM, de Swiet M, Osmond C, et al. Initiation of hypertension in utero and its amplification throughout life. BMJ 1993;306:24-7.

32 Law CM, Barker DJP, Bull AR, et al. Maternal and fetal influences on blood pressure. Arch Dis Child 1991;66:1291-5. 